\section{Isolation of Intact RNA Following Cryosection of Archived Frozen Tissue}

BioTechniques 34:48-50 (January 2003)

Advances in our understanding of the expression of particular genes during the course of various human diseases have led to an increasing need to obtain high-quality and intact RNA from tissue specimens to facilitate functional genomic investigations. The emergence of laser microdissection microscopy technology has allowed researchers to undertake such studies on specific cell populations consisting of relatively small numbers of cells that are dissected out of complex histological tissue sections (1). This, along with procedures that provide a means of extracting intact RNA from ever-decreasing numbers of cells, has enabled scientists to investigate the expression of genes in malignant cells from tumors without the confounding influence of nonmalignant tissue involvement (7).

To this end, collecting tissue for subsequent storage in appropriate biorepositories has become a standard operation within hospitals and research institutions around the world (3). Because of the labile nature of RNA, the most highly adopted procedure for the long-term storage of tissue involves snap-freezing the tissue in liquid nitrogen as soon after collection as possible to preserve the integrity of the RNA. The specimens are then stored at $-80^{\circ} \mathrm{C}$ (6). This protocol has been followed by The Children's Hospital at Westmead Tumour Bank (www.chw.edu.au/tumourbank) (3).

However, snap-freezing tissue is not always practical or reproducible and is known to disrupt tissue morphology that is crucial for specimen identification and disease diagnosis (8). By contrast, paraffin-embedding tissue specimens, which requires previous specimen fixation, preserves tissue morphology suitable for histological examination. Despite reports that RNA can be successfully extracted from formalinfixed tissue (2), fixation protocols are known to degrade RNA. The use of the aqueous tissue preservation solution
RNAlater ${ }^{\mathrm{TM}}$ (Ambion, Austin, TX, USA) has been developed to alleviate such difficulty (4). RNAlater is a proprietary histological fixative developed to preserve specimen RNA integrity while not modifying tissue morphology.

The RNAlater procedure has been reported to be the method of choice for the examination of gene expression associated with glaucoma using whole donor eyes (9). Similarly, the preservation of both RNA quality as well as tissue architecture has been shown to be comparable in neuroblastoma tumor tissue in specimens stored in this solution at room temperature and in snapfrozen tissue stored at $-70^{\circ} \mathrm{C}(6)$. Extensive gene expression analysis using RNA from RNAlater-treated breast cancer biopsy specimens demonstrated that the molecular profiles were unaffected by this tissue processing procedure (4). Application of RNAlater as part of the overall protocol for tissue bank specimens has also been recommended (5).

These cited reports demonstrate the effect of RNAlater on fresh tissue before frozen storage when used according to the recommended protocol. Thus, freshly obtained tissue is immersed in the solution for more than $1 \mathrm{~h}$ before snap-freezing with liquid nitrogen. Consequently, its application to tissue not treated with RNAlater but already stored in established tissue banks appears limited. We report results that allow for a modification of this protocol for the application of RNAlater that is contrary to the manufacturer's insistence that tissue should not be frozen before immersion in this solution (RNAlater Product Description version 0107; www.ambion.com) that will preserve RNA integrity and tissue morphology in archived frozen tissue.

Residual tissue was excised from mice that had been sacrificed during transgenic studies ongoing in our laboratory. To emulate our tumor banking procedure, excised whole kidneys were immediately placed in 2-mL cryovials, snap-frozen in liquid nitrogen, and stored at $-80^{\circ} \mathrm{C}$ for more than three months. Frozen kidney tissue was placed in cryomoulds and immersed in OCT medium before frozen-sectioning with a cryotome. To assess RNA integrity of our tissue sections, fifteen 10- $\mu \mathrm{m}$ sections were collected, placed into an Eppendorf ${ }^{\circledR}$ tube, and immediately covered with 1.5-mL RNAlater. A similar collection of sections were prepared and left in the absence of RNAlater as a control. The sections were allowed to soak in the solution for $1 \mathrm{~h}$ at room temperature, which was then carefully decanted and discarded. To remove any residual RNAlater and OCT medium, the sections were covered in $1 \mathrm{~mL}$ DEPC-treated water and briefly mixed by vortex mixing, followed by centrifugation at $10000 \mathrm{rpm}$ for $30 \mathrm{~s}$ at room temperature. The addition of water served to dilute the viscous RNAlater and facilitate its removal.

RNA was isolated using the RNeasy ${ }^{\circledR}$ RNA isolation kit (Qiagen, Valencia, CA, USA). The tissue sections were homogenized directly in the Eppendorf tube with $350 \mu \mathrm{L}$ lysis buffer using a small plastic pestle homogenizer. The tissue lysate was centrifuged at $12000 \mathrm{rpm}$ for $3 \mathrm{~min}$ at room temperature, and the supernatant was retained

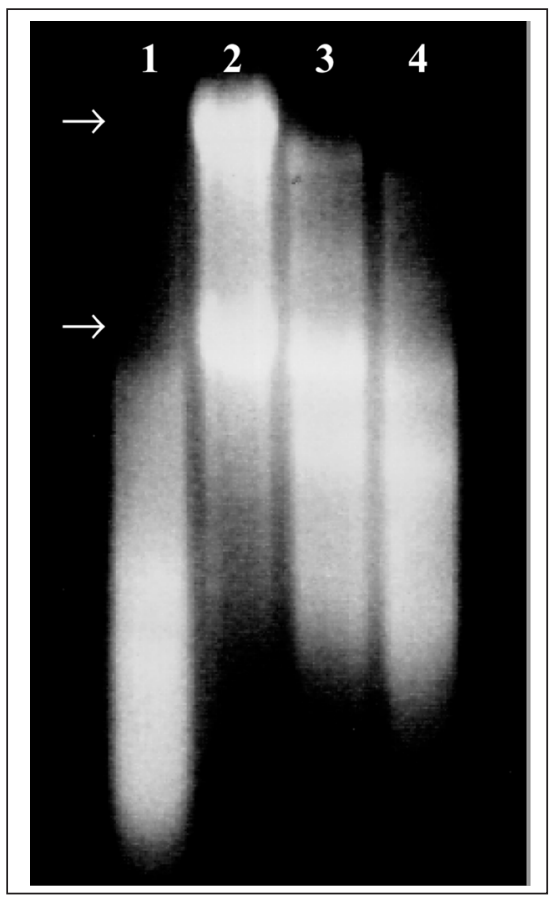

Figure 1. Preservation of RNA integrity in sections of snap-frozen murine kidney tissue. Following cryosectioning, RNA integrity, as evidenced by the $28 \mathrm{~S}$ and $18 \mathrm{~S}$ rRNA bands (arrows), is rapidly lost (lane 1) but is preserved when the sections are immediately placed in RNAlater for $1 \mathrm{~h}$ at room temperature (lane 2). RNA degradation is seen in mouse kidney sections removed from RNAlater and left at room temperature for 1 $\mathrm{h}$ (lane 3 ) and $2 \mathrm{~h}$ (lane 4) before RNA isolation. 
for subsequent RNA isolation steps, which were carried out according to the manufacturer's instructions.

Spectrophotometry was used to determine the purity and yield of the RNA isolated from the tissue sections. Neither preparation demonstrated significant variation with regard to RNA yield or purity $\left(\mathrm{A}_{260 / 280}\right.$ ratio), as determined by spectrophotometry. However, despite furnishing an average $\mathrm{A}_{260 / 280} \mathrm{ra}-$ tio of 1.91, snap-frozen mouse kidney tissue that had been prepared in the absence of RNAlater yielded completely degraded RNA upon examination by formaldehyde denaturing gel electrophoresis (Figure 1, lane 1). By contrast, we routinely obtain high-quality RNA from mouse kidney sections that had immediately been submerged in RNAlater and then left at room temperature for $60 \mathrm{~min}$. This was evidenced by the presence of intact $18 \mathrm{~S}$ and $28 \mathrm{~S}$ rRNA bands (Figure 1, lane 2).

Parlato et al. (8) reported that optimal RNA integrity was obtained following cryosectioning when the frozen tissue sections were stored at $-80^{\circ} \mathrm{C}$ before staining with a rapid protocol and laser microdissection. We wished to deter-

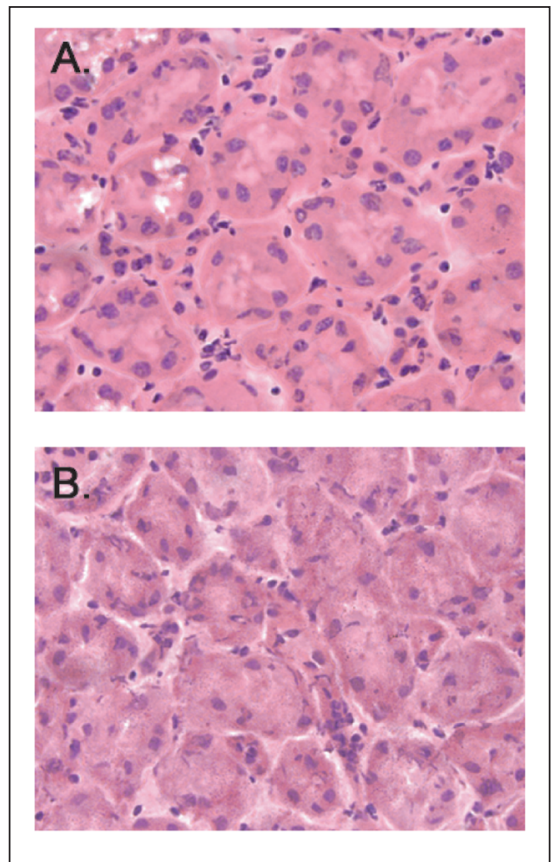

Figure 2. Preservation of kidney tissue histology. Maintenance of histologic integrity of normal mouse kidney, following cryosectioning and routine $\mathrm{H} \& \mathrm{E}$ staining (A), as well as following treatment of the tissue sections with RNAlater for $1 \mathrm{~h}$ at room temperature (B). mine whether RNAlater had a lasting effect on the RNA integrity that could be maintained during subsequent staining and laser microdissection applications. When we repeated the above procedure, upon removal of the RNAlater and a wash in $1 \mathrm{~mL}$ DEPC-treated water, the sections were allowed to stand at room temperature for a further 1 and $2 \mathrm{~h}$ before RNA isolation. As shown in Figure 1, lanes 3 and 4, a gradual loss of RNA integrity was observed. However, the rate at which the RNA degradation took place was qualitatively slower compared to when no RNAlater was used at all, suggesting that use of RNAlater in the manner described will have application as an alternative to storing slides in a freezer or when maintaining sectioned tissue frozen is neither appropriate nor practical.

A key requirement of tissue preservation solutions, especially if they are to be applied to laser microdissection of complex tissue such as tumors, is whether the tissue architecture and cellular morphology are maintained and whether key cellular structures can be identified (5). To test whether this modified application of RNAlater had any detrimental effect on tissue morphology, we compared slide mounted cryosections of normal mouse kidney treated in the presence or absence of RNAlater for $60 \mathrm{~min}$ at room temperature and subsequently stained using a routine hematoxylin-and-eosin (H\&E) histological protocol. Figure 2 demonstrates that, despite the sections being slightly grainier when RNAlater is used, the application of RNAlater to sections of tissue before staining caused no adverse change in tissue architecture, cellular morphology, or the ability to stain the tissue using routine $\mathrm{H} \& \mathrm{E}$ stains.

This study demonstrates a novel use for the tissue preservation, RNA stabilization fluid, RNAlater. Treating tissue cryosections with RNAlater will facilitate the development of staining and preparation protocols suitable for the laser microdissection of frozen archival tissue specimens.

\section{REFERENCES}

1.Bonner, R.F., M. Emmert-Buck, K. Cole, T.
Pohida, R. Chuaqui, S. Goldstein, and L.A.
Liotta. 1997. Laser capture microdissection: molecular analysis of tissue. Science 278:14811483.

2.Coombs, N.J., A.C. Gough, and J.N. Primrose. 1999. Optimisation of DNA and RNA extraction from archival formalin-fixed tissue. Nucleic Acids Res. 27:e12.

3.Coupland, L.A., C.M. Cooke-Yarborough, and L. Dalla-Pozza. 1999. The New Children's Hospital Tumour Bank. Med. J. Australia 170:284-285.

4.Ellis, M., N. Davis, A. Coop, M. Liu, L. Schumaker, R.Y. Lee, R. Srikanchana, C.G. Russell, et al. 2002. Development and validation of a method for using breast core needle biopsies for gene expression microarray analyses. Clin. Cancer Res. 8:1155-1166.

5.Florell, S.R., C.M. Coffin, J.A. Holden, J.W. Zimmermann, J.W. Gerwels, B.K. Summers, D.A. Jones, and S.A. Leachman. 2001. Preservation of RNA for functional genomic studies: a multidisciplinary tumor bank protocol. Mod. Pathol. 14:116-128.

6.Grotzer, M.A., R. Patti, B. Geoerger, A. Eggert, T.T. Chou, and P.C. Phillips. 2000. Biological stability of RNA isolated from RNAlater-treated brain tumour and neuroblastoma xenografts. Med. Pediatr. Oncol. 34:438442.

7.Luo, L., R.C. Salunga, H. Guo, A. Bittner, K.C. Joy, J.E. Galindo, H. Xiao, K.E. Rogers, et al. 1999. Gene expression profiles of laser-captured adjacent neuronal subtypes. Nat. Med. 5:117-122.

8.Parlato, R., A. Rosica, V. Cuccurullo, L. Mansi, P. Macchia, J.D. Owens, J.F. Mushinski, M. De Felice, et al. 2002. A preservation method that allows recovery of intact RNA from tissues dissected by laser capture microdissection. Anal. Biochem. 300:139-145.

9.Wang, W-H., L.G. McNatt, A.R. Shepard, N. Jacobson, D.Y. Nishimura, E.M. Stone, V.C. Sheffield, and A.F. Clark. 2001. Optimal procedure for extracting RNA from human ocular tissues and expression profiling of the congenital glaucoma gene FOXC1 using quantitative RT-PCR. Mol. Vis. 7:89-94.

Address correspondence to Dr. Daniel R. Catchpoole, The Tumour Bank, The Children's Hospital at Westmead, Locked Bag 4001, Westmead, NSW, 2145, Australia. email:danielc@chw.edu.au

Received 8 August 2002; accepted 25 October 2002.

\section{Dachuan Guo and Daniel R. Catchpoole \\ The Children's Hospital at Westmead \\ Westmead, NSW, Australia}

